\title{
Featured Correspondence
}

\section{Transcatheter closure of perimembranous ventricular septal defect}

To the Editor: Increasing concerns about the potential for atrioventricular (AV) block after transcatheter closure of perimembranous ventricular septal defect (VSD) were emphasised by Ian Sullivan in a recent issue of Heart. ${ }^{1}$ This complication has been highlighted in a clinical series published by Walsh et al. ${ }^{2}$ Their patients developed heart block after closure of perimembranous VSD (pmVSD) within 10 days of the procedure. Because of two instances of very late onset of complete atrioventricular block (cAVB) 24 and 39 months, respectively, after successful and uncomplicated percutaneous closure of pmVSD using the asymmetrical Amplatzer pmVSD occluder (AGA Medical, Golden Valley, Minnesota, USA), all patients who underwent percutaneous closure of pmVSD were reviewed at our institution (The Royal Children's Hospital, Melbourne, Victoria, Australia). Of 36 patients who had undergone interventional pmVSD closure, 3 patients developed AV block requiring permanent pacemaker implantation. One patient developed cAVB within 6 days of closure, presenting with syncope and hypotensive seizures. After implantation of a permanent pacemaker, his AV conduction normalised. Another patient who presented with tiredness at 24 months after intervention had AV block with 2:1 conduction and periods of cAVB. Another recent patient had intermittent CAVB 39 months after the procedure, and fatigue and dizziness for 5 months identified only after focused interrogation. Holter monitoring showed frequent periods of AV block with 2:1 conduction, Mobitz type II and intermittent cAVB (fig 1). The longest pause was for $9.6 \mathrm{~s}$. Both patients required permanent pacemakers; their conduction has not normalised. Because of the late onset and severity of symptoms, we did not attempt steroid therapy. ${ }^{3}$ The incidence of cAVB in our patient cohort is $8.3 \%$ compared with $1-5 \%$ report in published data. ${ }^{24}$ After the first instance of late CAVB, we ceased our programme of interventional pmVSD closure. Despite routinely performed preinterventional and postinterventional Holter monitoring, we have recalled all patients for ECG and Holter monitoring. Late onset of CAVB in children, after interventional closure of pmVSD, has been reported. ${ }^{6}$ Very late onset has been reported only after surgical closure. ${ }^{78}$ It is important to be alert to the unpredictability and high incidence of very late onset of this potentially fatal complication and to recommend that $\mathrm{AV}$ conduction be followed carefully. It is time for all units performing this procedure to consider whether it is ever indicated with the currently available device.

Anita Dumitrescu, Geoffrey K Lane, James L Wilkinson, T H Goh, Daniel J Penny, Andrew M Davis

Department of Paediatric Cardiology, The Roya Children's Hospital, Melbourne, Victoria, Australia

Correspondence to: Dr A Dumitrescu, The Royal Children's Hospital, Melbourne, Flemington Road Parkville, VIC 3052, Australia; anidumitres@yahoo.com

doi: 10.1136/hrt.2007.119461

Competing interests: None declared

\section{References}

1 Sullivan ID. Transcatheter closure of perimembranous ventricular septal defect: is the ris of heart block too high a price? Heart 2007;93:284-6.

2 Walsh MA, Bialkowski J, Szkutnik M, et al. Atrioventricular block after transcatheter closure of perimembranous ventricular septal defects. Heart 2006:92:1295-7.

3 Yip WC, Zimmerman F, Hijazi ZM. Heart block and empirical therapy after transcatheter closure of perimembranous septal defect. Catheter Cardiovasc Interv 2005;66:436-41.

4 Masura J, Gao W, Gavora P, et al. Percutaneous closure of perimembranous ventricular septal defects with the eccentric Amplatzer device: multicenter follow-up study. Pediatr Cardiol 2005;26:216-19.

5 Arora R, Trehan V, Kumar A, et al. Transcatheter closure of congenital ventricular septal defects: experience with various devices. J Interv Cardiol 2003;16:83-91.

6 Butera G, Chessa M, Carminato $M$, et al. Late complete atrioventricular block after percutaneous closure of a perimembranous ventricular septal defect. Catheter Cardiovasc Interv 2006:67:938-41.

7 Fukuda T, Nakamura Y, lemura J, et al. Onset of complete atrioventricular block 15 years after ventricular septal defect surgery. Pediatr Cardiol 2002;23:80-3.

8 Roos-Hesslink JW, Meiiboom FJ, Spitaels SEC, et al. Outcome of patients after surgical closure of ventricular septal defect at young age: longitudinal follow-up of 22-34 years. Eur Heart $J$

2004; 25: 1057-62.

The author's reply: The letter from Melbourne by Dumitrescu et al reporting complete heart block occurring in 3 of 36 patients after transcatheter closure of perimembranous ventricular septal defect adds weight to the concern expressed about this complication. ${ }^{1}$ Most disturbing is the detection of new-onset heart block more than 3 years after the interventional catheter procedure. This supports the view that steroid treatment in the immediate postimplantation period will not necessarily prevent the late development of this important complication. The age or size of the affected patients at the time of device implantation is not stated, but all were children.

Interventional catheterisation occlusion of a perimembranous ventricular septal defect in children, whether using the existing asymmetric Amplatzer occluder or other occlusive devices, should be performed with caution, and only as part of a prospective clinical trial or with submission of data to a registry. Continuing follow-up of patients who have undergone the procedure is required. There is a responsibility to alert patients and their families to seek advice should relevant symptoms suggesting bradycardia occur, and also to report further experience of heart block should this be recognised. If similar experience of lateonset heart block becomes widespread, the question of prophylactic pacemaker insertion may even need consideration.

Ian Sullivan

Correspondence to: Dr I Sullivan, Great Ormond Stree Hospital for Children NHS Trust, Great Ormond Street, London WC1N 3JH, UK; sullii@gosh.nhs.uk

Competing interests: None declared.

\section{Reference}

1 Sullivan ID. Transcatheter closure of perimembranous ventricular septal defect; is the risk to heart block too high a price? Heart 2007;93:284-6.

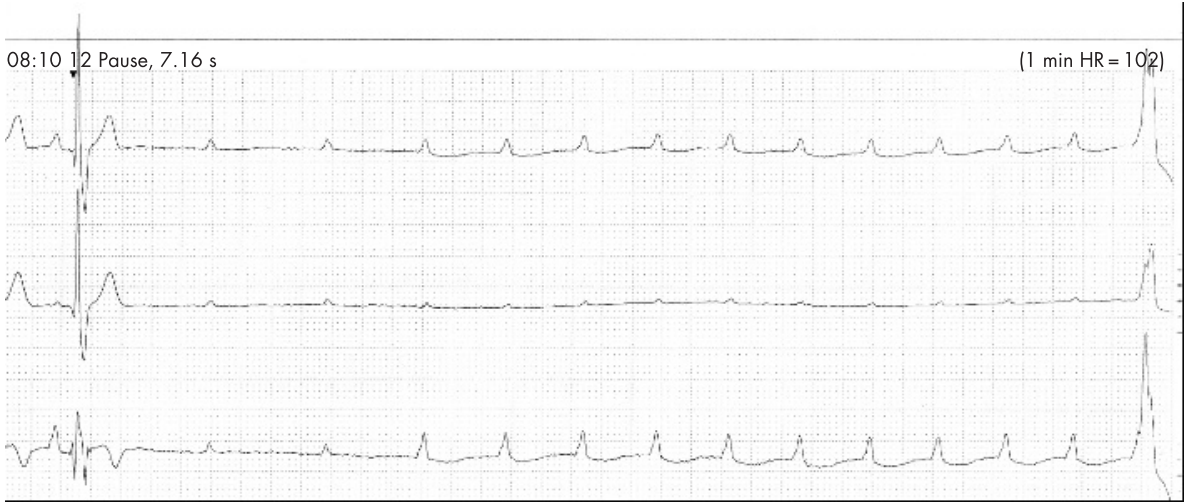

Figure 1 Intermittent cAVB 39 months post intervention. 